\title{
Las causas de la crisis financiera del sistema de salud colombiano desde los medicamentos*
}

\author{
The causes of financial crisis of the Colombian \\ health system from the medicines
}

\begin{abstract}
Oscar-Iván Andia ${ }^{1}$
Forma de citar: Andia OI. Las causas de la crisis financiera del sistema de salud colombiano desde los medicamentos. Rev Univ Ind Santander Salud. 51(4): 277-278. doi: http://dx.doi.org/10.18273/revsal.v51n4-2019009 @) (1)

Desde hace 10 años ya se podía evidenciar la crisis del sector salud. Una forma de ver los cambios ocurridos desde esa época hasta la actualidad, es analizando los datos del mercado farmacéutico de 2012 a 2018. Lo primero que puede identificarse es que el mercado no crece realmente en unidades, crece solamente en valores. Y al ver la diferencia de lo que está incluido o no en el Plan Obligatorio de Salud (POS), lo que se observa es un crecimiento en el No-POS. Es decir, el mercado de medicamentos en Colombia está estable, para decirlo de manera positiva, y lo único que crece es el No-POS. El No-POS es el cáncer del sistema de salud colombiano. Como consecuencia de lo anterior, las unidades disponibles para la atención en salud se mantienen iguales, mientras las ganancias de los laboratorios farmacéuticos aumentan, por el aumento de precios y el incremento de venta de productos más costosos.

La regulación de precios de medicamentos fue una política pública exitosa pero ya fue neutralizada. Hay dos ejemplos útiles para ver el fenómeno: Dos de los medicamentos más recobrados fueron el Rituximab (anticuerpo monoclonal usado para tratar el Linfoma no Hodgkin y la leucemia linfocítica crónica) y el Trastuzumab (anticuerpo monoclonal usado para diversos cánceres, especialmente el de mama). El precio de estos medicamentos creció exageradamente hasta el año 2011 y, luego, se logró la reducción del precio, a niveles de 2002, mediante regulación por valores máximos de recobro, precios de referencia internacional e inclusión en el POS. Pero esta regulación ya fue neutralizada mediante cambios en el mercado que mantienen las ventas de la industria farmacéutica. El caso del Rituximab es dramático. Un medicamento con indicación oncológica que cuando el precio fue regulado pasó a ser promocionado como tratamiento de la artritis reumatoidea, con lo que logró vender muchas más unidades, neutralizando así la regulación de precios. El Trastuzumab también logró estabilizar el número de unidades y aumentó sus ventas lanzando nuevas presentaciones comerciales, nuevas concentraciones y mezclas con otras moléculas. La consecuencia de este último cambio fue la duplicación del precio.
\end{abstract}

Sumado a esto, también hubo fallas en la regulación. Un buen ejemplo es el caso del tratamiento de la leucemia mieloide crónica; el Imatinib fue por varios años el medicamento de elección y cuando su precio fue regulado, el costo del tratamiento de la enfermedad se mantuvo estable, al incluirse el Nilotinib del mismo laboratorio farmacéutico, con precio sustancialmente mayor. En conclusión, la leucemia mieloide crónica le sigue costando al sistema de salud lo mismo que siempre. Esto ha ocasionado que independientemente de la regulación, al Estado le cueste lo mismo el tratamiento de un paciente.

Junto con los medicamentos biotecnológicos y oncológicos; los recobros crecen con las enfermedades huérfanas, como en el caso de la Lomitapida (inhibidor selectivo de la proteína de transferencia microsomal, cuyo nombre comercial es Juxtapid), medicamento usado para tratar la hiperlipidemia familiar homocigótica. En este caso, para

1. Federación Médica Colombiana.

Correspondencia: Oscar Andia. Dirección: Cra.47A No. 114A-39 Bogotá. Teléfono: +57 3044038009 Correo electrónico: observamed.fcm@gmail.com

* Documento basado en la conferencia realizada en la Facultad de Salud de la Universidad Industrial de Santander el día 6 de 2019, como parte del II Simposio Crisis de la Salud en Colombia. IPSs y ley de punto final. 
mantener a un paciente sus cifras de colesterol en valores normales durante 28 días, se le tiene que administrar un frasco de 28 cápsulas de este medicamento, cuyo precio es de $\$ 120$ millones cada frasco. Aquí vemos un tema no resuelto, que es la confrontación del derecho individual versus el derecho social. Hay actores con poder interesados que están hiper-explotando lo que es el derecho individual a costa del derecho social de miles de niños que no tienen acceso a agua potable y saneamiento básico. Otro caso, la Elosulfasa alfa (versión sintética de la enzima $\mathrm{N}$-acetilgalactosamina-6-sulfatasa, cuyo nombre comercial es Vimizim) que es usada para el tratamiento del síndrome de Morquio. Aquí al administrar el medicamento, obviamente, no cambian características clínicas como la baja talla o deformidades de la columna vertebral, solo mejora un poco el desplazamiento. Para el manejo de 100 de estos pacientes, usando cifras redondas, el sistema ha pagado cerca de \$200 mil millones, un derroche del recurso del sistema en función del derecho individual frente a la ausencia de recursos para el derecho social.

El No-POS crece también por falsa innovación tecnológica, como con Alemtuzumab. Este medicamento inicialmente fue tratamiento de la leucemia linfocítica crónica, y en Colombia tenía una presentación comercial de 90 miligramos con un costo de $\$ 4,5$ millones. Luego fue descontinuado y reapareció con indicación de tratamiento de la esclerosis múltiple; sin embargo, la nueva presentación fue de 12 miligramos y un precio de \$23 millones.

Y para entender mejor el impacto de los medicamentos No-POS en la crisis del sector salud digamos que los recobros antiguos se hacían con productos como Adalimumab, Bevacizumab, Rituximab, Trastuzumab, etcétera, cuyo precio no superaba los $\$ 10$ millones por unidad. Ahora los precios de medicamentos que se están recobrando superan los 20 y 30 millones. Por ejemplo, Canakinumab $150 \mathrm{mg}$ (Ilaris) a $\$ 24,6$ millones (pese al precio regulado de $\$ 36,6$ millones), Ruxolitinib $20 \mathrm{mg}$ (Jakavi) a \$19,2 millones (precio regulado \$20,7 millones) y ahora Dabrafenib $75 \mathrm{mg}$ (Tafinlar) a \$18,4 millones y Trametinib $2 \mathrm{mg}$ (Mekinist) a \$11,8 millones, Emicizumab (Emlibra) y Ocrelizumab (Ocrevus) con precios de \$29 millones y \$17 millones por vial respectivamente, sin ningún tipo de regulación. Y ya tenemos recobros de Nusinersen (oligonucleótido antisentido, cuyo nombre comercial es Spinraza), medicamento usado en el tratamiento de la atrofia muscular espinal. Por un solo paciente en agosto se han recobrado tres viales y el sistema de salud ha pagado $\$ 1.123$ millones.

Los beneficios que obtienen los laboratorios farmacéuticos con estos productos, son exageradamente superiores a los resultados en salud para los pacientes. Existen redes de recobro que han tenido éxito, y están llevando al sistema de salud a su colapso; ningún sistema soporta esto. La tendencia es a seguir empeorando porque hay una estrategia definida a nivel global para el manejo de este tipo de productos, y Colombia es una víctima preferida porque hay un empoderamiento del derecho fundamental a la salud y no hay señales de que como sociedad se pueda mejorar esta relación entre el derecho individual y el derecho social. Aquí abundan los abusos en función del derecho fundamental a la salud mal entendido, en función de la autonomía médica mal entendida, en función de una ineficiente autorregulación de los médicos cuando prescriben este tipo de medicamentos.

También hay captura de la regulación, por una "integración profunda con dientes". Se están maximizando los criterios de las normas técnicas para una supuesta mejor calidad en los servicios de salud, y con ese pretexto se elimina la competencia y se suben desmesuradamente los precios. Y hasta captura de medios de comunicación. Resulta inadmisible que en nombre de una publicación de prestigio como la Revista Semana se haga un evento especial para llamar "biolimbos" (y en voz baja "biochimbos") a los biogenéricos, medicamentos biosimilares o competidores de los medicamentos biotecnológicos.

Frente a este panorama desolador, la actual administración está mostrando lo que podemos llamar una "hipotonía regulatoria" con solo tres Circulares y la Resolución 1019: a) Circular 07 de 2018 que en realidad es del anterior gobierno, b) Circular 08 de 2018 que solo ajustó la regulación de 118 CUM, de los cuales solo 11 están realmente disponibles, c) Circular 09 de 2019 que reguló solo un par de anticonceptivos y d) Resolución 1019 de 2019 que fijó Valores Máximos de Recobro VMR para 50 principios activos. Así llegamos a unos Valores Máximos de Recobro (VMR) que el mismo gobierno dice "no son regulatorias", un Acuerdo de Punto final para reconocer deudas dudosas del sistema de salud a las EPS y los Techos de recobro, que consagran a las EPS como "gestoras y administradoras” del NoPOS, hoy NoPBS. La estrategia está clara: Débil regulación y más empoderamiento para los actores con poder. 